\title{
Improve Performance of Wing Plan by Gettingnd of the Boundary Layer Control Using Electric System
}

\author{
Asst.Pro. Dr. Nazhat Saeed $\dagger$, Dr. Yasser Ahmed ${ }^{\ddagger}$ and Basmah. T.dawod \\ $\dagger$ Dept.of Electromechanical Engineering, University of Technology/ Al-Sinaa' Street, 10066, Baghdad, Iraq \\ Dept.of Electromechanical Engineering, University of Technology Al-Sinaa' Street, 10066, Baghdad, Iraq \\ ${ }^{\mathrm{T}}$ Dept.of Electromechanical Engineering, University of Technology/ Al-Sinaa' Street, 10066, Baghdad, Iraq
}

\begin{abstract}
The amount of drag produced significantly depends on shape of the airfoil. These implementation concerns the lift and drag analysis of three different profiles of airfoils, which are symmetrical aerofoil (NACA 0015, NACA0012) and cambered aerofoil (NACA 4415) have different volume. NACA0015 is provided with perforated tube fixed at $75 \%$ from the leading edge for suction. Electrical control system used to control the suction operation the three different types of objected has been tested at a sub-sonic wind tunnel and experimental data has been obtained at different Reynolds's number and angle of attack. The three airfoils (symmetrical NACA 0015, NACA0012 and cambered with NACA 4415) tested at $\left(0^{0}, 5^{0}, 10^{\circ}, 15^{0}\right.$ and $\left.18^{\circ}\right)$ angles of attack. All the three objects tested at $\operatorname{Re}\left(1.72,2.9,4,5.2\right.$ and $\left.6.3 \times 10^{5}\right)$. The cambered airfoil has been given least drag among than all the airfoils. The drag force of all test model are decreased when the value of Reynolds number are increased and NACA 4415 exhibit less drag and high lift in comparison with other models that used in this study. Suction technique is more active at lower values of $\mathrm{Re}$-number.
\end{abstract}

Keywords: Wind Tunnel, Drag Coefficient, Aero foil, Reynolds number

\section{Introduction}

Power saving is one of the most important parameter in design of air plane. Relative motion between the immersed bodies and fluid tend to induce two types of forces; one is a result of the pressure distribution changing called the lift force [1]. Surface friction and tangential shear stress caused the other type of forces which called drag force. Drag force has passive effects on the aerodynamic characteristics of the immersed bodies. To certify these effects three different types of profile of airfoil studied in the current paper. NACA 0015, NACA0012 and NACA 2412are used with different air speed and attack angle. Many authors studied passive and active means to control flow separation. Approaches involve vortex generators. Brandt was the first scientist who employed boundary layer suction to indicate its significant impacts on stream lines in 1904. He used. Some of the most common suction on cylindrical surface to delay boundary layer separation. Boundary layer separation would be eliminated almost entirely by suction through a slot on the back of the cylinder[2].A boundary layer is the thin region of flow adjacent to the surface, the layer in which the flow is influenced by the friction between the solid surface and the fluid [3]. Aircraft wings are mainly intended to provide the maximum value of the lift-to-drag ratio $\mathrm{L} / \mathrm{D}$. The $\mathrm{L} / \mathrm{D}$ ratio is deemed as a measure of the efficiency of an aircraft [4] and can be stated as the amount of power (thrust) that is required to impel an aircraft of a certain weight. The $\mathrm{L} / \mathrm{D}$ value is a measure of the efficiency of an aircraft [5] which can be expressed as the amount of power (thrust) that is required to propel an aircraft of a certain weight. There have been some experimental as well as theoretical studies on influence of different wing configurations on the aerodynamic characteristics [6]. Potential flow, cascade, vortices and vortex transport models [7]. The passive flow control means that the flow control is applied only by deflecting the control surfaces and no energy is added to the flow [8]. Have studied the effect of active control on boundary layer separation, pressure coefficients, lift and drag coefficients. Buchmann et al [9].The select different shape of profile give good imaging to determine the best shape of effected wetted area that leads to reduce the value of drag coefficient. Reduce the wetted aria is significant factors in design of turbine blade and the other stream line bodies applications. Also the effect of speed and angle of attack take into account.

\subsection{Streamlined Bodies Definitions}

Airfoil may be symmetrical or unsymmetrical as shown in the figure (2.1). Some of the definition relating airfoil given below:

- Chord line. It's the line connecting the leading edge and trailing edge.

- Centreline of profile. It's the line connecting the midpoints of the aerofoil.

- Attack angle. It's the angle between the direction of stream lines and chord line. 
- Camber. It's concerned of the unsymmetrical aerofoil and represents the curvature of airfoil.

- Stall. An aerofoil is side in the stall conditions when the aerofoil attack angle is more than the attack angle that achieve maximum lift. Separation occurs from boundary surface and tend to form eddies. Also there is increase in the drag co-efficient.

- Aspect ratio (A.R). The ratio between the length of span (L) and the length of the chord (c).

$$
A \cdot R=\frac{L}{C} \ldots \cdots \cdots
$$

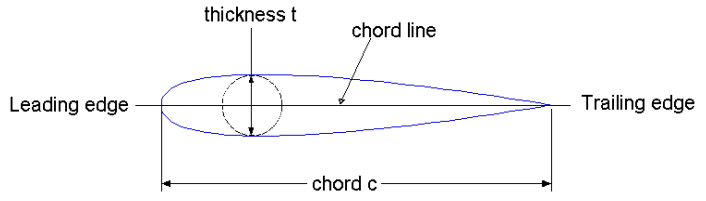

(a)

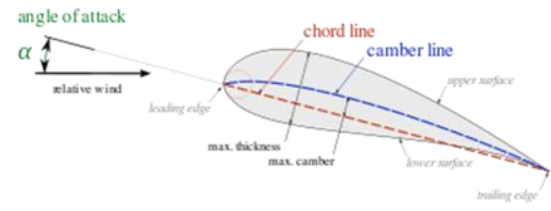

(b)

Figure (1): Airfoil type a. symmetrical airfoil, b. unsymmetrical airfoil

Airfoil are designed by 4-digit, 5-digit, modified 4-/5digit, 6-digit etc. This paper focused on the 4- digit design of NACA airfoil shapes. This digit can be explanation:-

a. The first digit specifies the maximum camber in percentage of the chord.

b. The second digit indicates the position of the maximum camber in tenths of chord

c. The last two digits provide the maximum thickness of the air foil in percentage of chord the thickness distribution above (+) and below (-) the mean line can be calculated by the following equation for each of the $\mathrm{x}$ coordinates of 4-digit NACA symmetrical aerofoil.

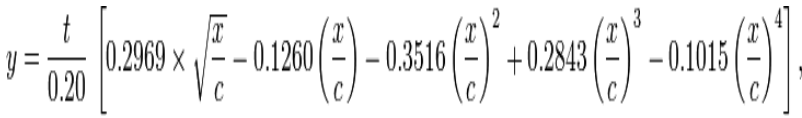

- $c$ is the chord length,

- $x$ is the position along the chord from 0 to $c$

- $y$ is the half thickness at a given value of $x$ (centerline to surface), and
- $T$ is the maximum thickness as a fraction of the chord (so $100 t$ gives the last two digits in the NACA 4-digit denomination) [10].

\section{2 lift and drag of an airfoil}

Figure (2.2) shows the aerodynamic forces that effected on the amerced bodies when the relative is exist. When the airfoil tilt in the certain attack angle The resultant of these forces are resolved into two perpendicular components termed lift and drag force.

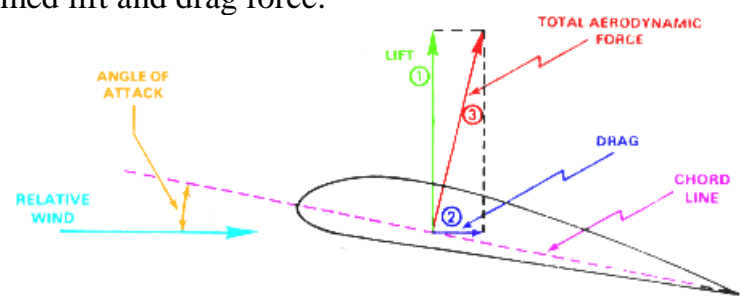

Figure (2): Aerodynamic forces on a typical airfoil

$$
F_{L}=C_{L} A \frac{\rho U^{2}}{2}
$$

Here, $F_{L}$ is the lift force, $C_{L}$ lift force, $\rho$ is the Density of air, $\mathrm{U}$ is the Velocity of the body and $\mathrm{A}$ is the Area of the body or aerofoil.

$$
F d=C_{d} A \frac{\rho U^{2}}{2} \ldots \ldots \ldots . .
$$

Where $\mathrm{Fd}$ is the drag force, $\mathrm{C}_{\mathrm{d}}$ drag coefficient

\section{Aerodynamic Features of Three Models}

Important features of experimental design of three major profiles, symmetric aerofoil (NACA 0015, NACA 0012) cambered aerofoil NACA 4415 are shown below.

\subsection{Test Model NACA 0015}

The section of wing chosen in the current study was NACA 0015(symmetrical cross-section with a thickness to chord ratio $\mathrm{t} / \mathrm{c}$ ratio of $15 \%$ with $0 \%$ the percentage of camber) with $(300 \mathrm{~mm})$ chord length and (300mm) span length, wood material used to manufacture the test model. Upper surface of described model is developed with $(10 \mathrm{~mm})$ slot along the span lay about $75 \%$ from the chord length to fix the suction tube, this tube was fabricated from copper and had five $(3 \mathrm{~mm})$ diameter holes with $6.25 \mathrm{~mm}$ pitch between the holes see figure (3.1). Sucker is achieved by hermetic type compressor. Piezo electric ceramic type was used to sense the changing (2.2)of pressure at stall condition as shown in figure (3.2) Sensors fixed in predetermined location on the upper surface of model in front of the suction tube. Figure (3.3) represent the schematic diagram for controlling circuit which used to control the suction operation. 


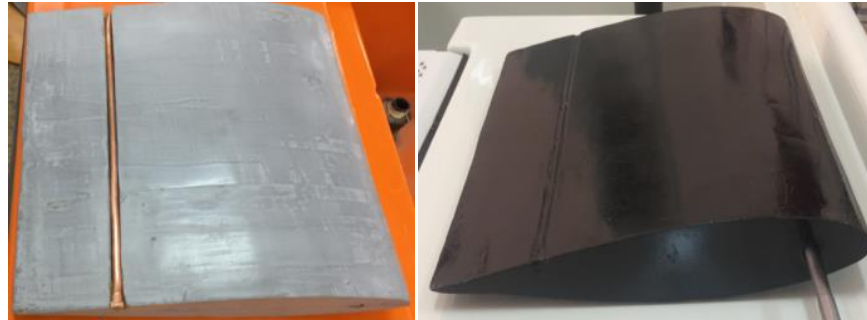

Figure (3): NACA 0015 Symmetric air foil

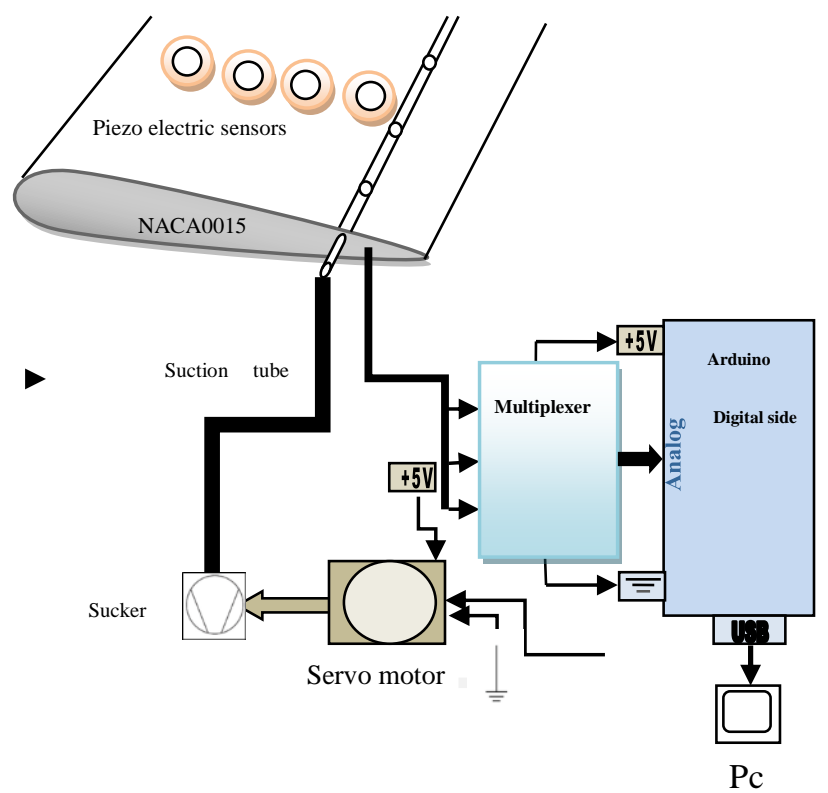

Figure (4): Schematic diagram represent control circuit to control on the suction operation of NACA0015.

Control system as shown in figure (3.2) consists of many electronic parts were used to build control circuit detail below:

-Pressure sensors: eight pressure sensors type BMP180 were used to deduct the change of the pressure in the current experiment. Two of these pressure sensors fixed on the Pitot - static tube used to measure the stagnation and static pressures at the tunnel entrance difference between them indicates to the dynamic pressure $(\Delta p)$ that used in the equation (3.1). This difference of pressure calibrated with pitot- tube measurement. Other six sensors is divided into three were fixed on the surface of model along the chord at mid of span with constant pitch to sense the change of pressure and determine the separation site. The other two sensors used to determine the angle of attack one of them was fixed on side wall of tunnel at on the zero line. The eighth sensors were fixed on the upper wall of the tunnel used with surface sensor to measure the pressure difference. This entire sensor connected to the Arduino by Multiplexer to transmit the analogue signals -Arduino: UNO type was used as a microcontroller circuit. The important specification of this type of microcontroller system detail bellow:
- Have 14 inputs and output digital port can be modified to fix pins as needed. Six of these pins can be used as output pulse width modulation (PWM) this technique is commonly used to generate square digital signal, the other six used inputs see figure (3.9).

- Arduino developed by $16 \mathrm{MHZ}$ quartz crystal m, USB connector to facilitate connect with computer. Also it's contained a DC power adapter between ( 7 to 12 ) with $250 \mathrm{~mA}$, SPI bus represent the expansion of the output and a reset button.

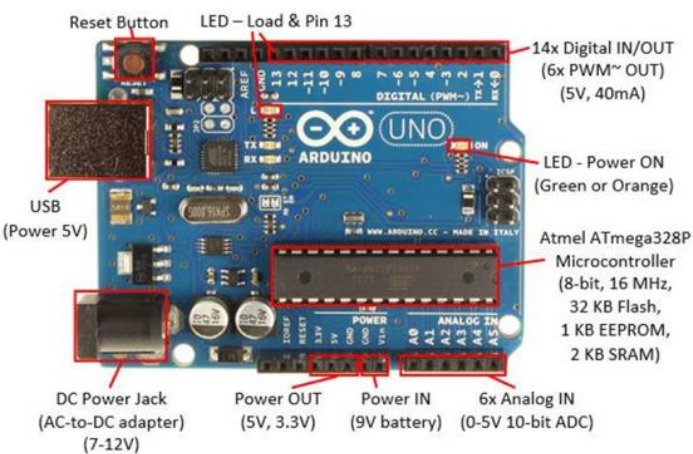

Figure (5): Arduino UNO type

\subsection{NACA 0012}

Figure (3.3) shows the NACA0012 standard experimental model from TQ - Equipment England in the fluid and gas dynamic lab of mechanical department in the college of engineering of Thi-Qar University. The dimensions of model are $300 \mathrm{~mm}$ and $150 \mathrm{~mm}$ chord and span length respectively. Plastic and aluminium the materials were used to make NACA 0012 test model.

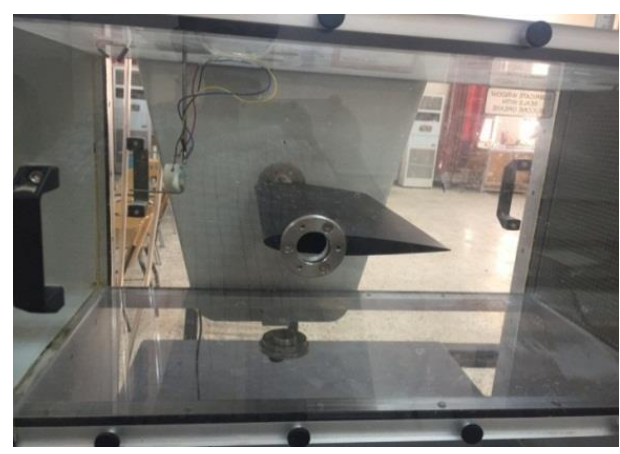

Figure (6): NACA0012 model

\subsection{NACA 4415}

Figure (3.4) represents the cambered airfoil NACA 4415 with Chord length $=142.67 \mathrm{~mm}$ and $\mathrm{Span}=247 \mathrm{~mm}$, thickness $=2.393 \mathrm{~mm}$. This section is manufactured from coated laminated wood in the fluid and gas dynamic lab of mechanical department engineering Thi- Qar University. Section developed by perforated tube at $\mathrm{x} / \mathrm{c}=80 \%$ from leading edge to conduct blowing experiment, in this study enhancement applied only the NACA0015 and NACA 4415 will used as conventional section. 


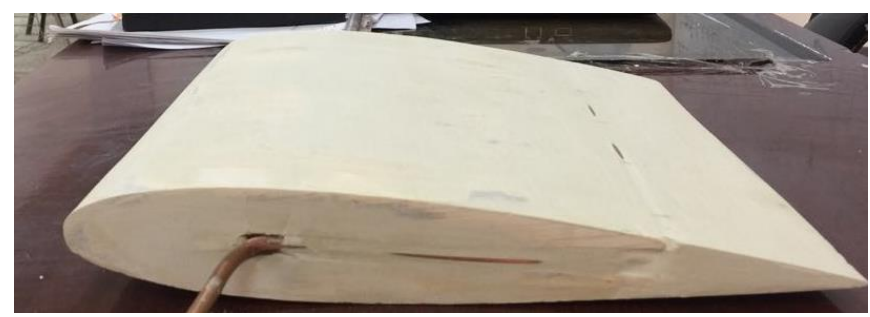

Figure (7) NACA 4415 model

All three models are tested under the same condition except NACA0015 is experienced twice, once test without active control by suction the delayed layer to determine the stall location the other test applied with suction to enhancement the aerodynamic characteristic and comparison with other models. Table (1) represents the testing parameters

Table (1): testing parameters

\begin{tabular}{|l|c|}
\hline \multicolumn{1}{|c|}{ Parameter } & Values \\
\hline Reynolds Number & $(1.72,2.9,4,5.2,6.3) \times$ \\
$10^{5}$
\end{tabular}

\subsection{Subsonic Wind Tunnel}

Open type wind tunnel was used in this work is subsonic wind tunnel manufactured by Equipment. Work section is made from acrylic Perspex to facilitate test section vision. The dimensions of work were $(300 \times 300 \times 600) \mathrm{mm}$. All roofs are smooth. Each side of test section can be removed to support the models which delivery with the tunnel. The top roof of the working section supplied with two holes for Pitot tube fixing also there is two walls tapping to measure the static pressure upstream and downstream of the working section. Drag and lift forces measured by single component balance. After wind tunnel and measurement devices set up experiments conducted at different air velocity and angles of attack (AOA) as in the Table (1). Figure (3.5) shows wind tunnel used in this experiment.

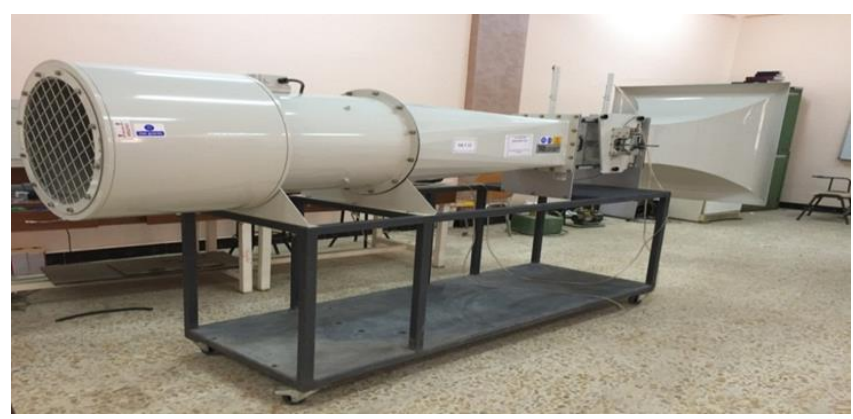

Figure (8): Sub- Sonic Wind Tunnel

Wind tunnel supplied with U- tube manometer to measure an air velocity in this case the difference of pressure between the stagnation pressure which measured by pitot tube and static pressure by wall tapping. Equation (3.1) to calculate the air velocity

$$
U=\sqrt{\frac{2 \times \Delta h \times 9.81}{\rho_{a}}} .
$$

$\mathrm{U}=$ velocity of air

$\Delta \mathrm{h}=$ dynamic pressure $(\mathrm{mmH} 2 \mathrm{o})$

$\rho=$ air density $(\mathrm{kg} / \mathrm{m} 3)$

\section{Result and Discussion:}

\subsubsection{Aerodynamic Characteristics of NACA 0015 without Enhancement}

Figure (4.1) shows the how Reynolds number effect on the values of drag coefficient aerofoil NACA 0015 when test the model without suction. There is slightly decreasing in the drag coefficient when increasing speed of the air (or Reynolds number) at each angle of attack. Also increasing angle of attack (AOA) tends to increase the values of the drag coefficient correspondingly. After $10^{\circ}$ AOA the drag coefficient (CD) increases dramatically. Figure (4.2) shows the variation of the lift coefficient with angle of attack (AOA). Stall condition appeared between $10-15^{\circ}$ of AOA approximately at $14^{\circ}$ angle of attack special at low Reynolds number. Determine the separation angle and point is most significant to fix the pressure sensors when using flow control system...

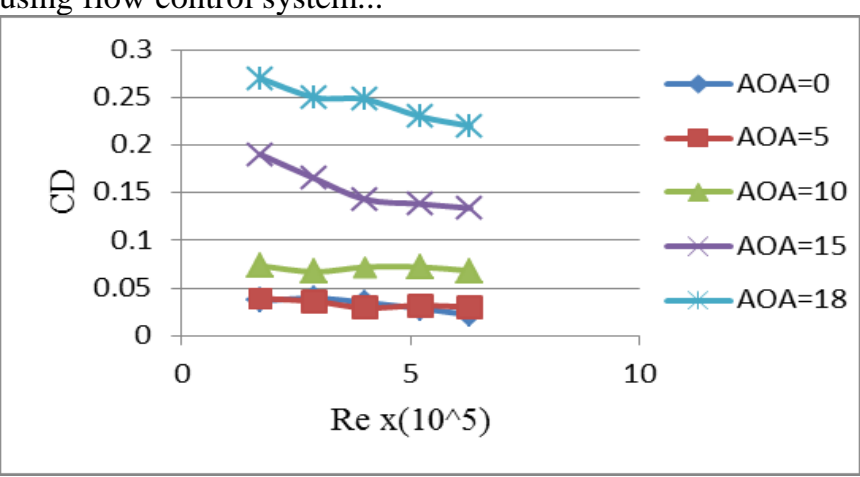

Figure (9): variation of drag coefficient (CD) with air velocity at different angle of attack of NACA 0015.

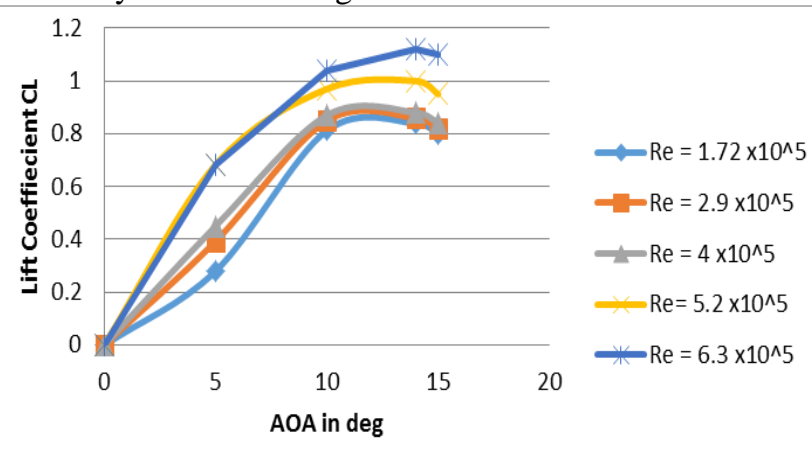

Figure (10): Variation of the lift coefficient with angle of attack of NACA 0015 without suction. 


\subsubsection{Aerodynamic Characteristics of NACA 0015 with suction.}

Suction of stalled boundary layer is one of these active techniques and its effect is twofold. At lower Re- number the laminar boundary layer will be morally stabilized his stopping transition and lead to larger areas of laminar flow, which generate less drag and reduce the lift coefficient. On the contrary, turbulent boundary layer separation will be postponed, resulting in a higher maximum lift coefficient. Delayed the boundary layer was more clearly when experiment the NACA0015 at lower Re-number(1.72, 2.9 and $4 \times 10^{5}$ ) see figure(4.2) and separation will occurred in this time pressure sensor sensed the change in the pressure then the magnitude of the pressure change analysed by controller that decided the start of suction operation. Figure (4.3) shows the enhancement the lift of the NACA0015. Suction more active with low Re- value, but there was slightly increase lift at large value of Re.

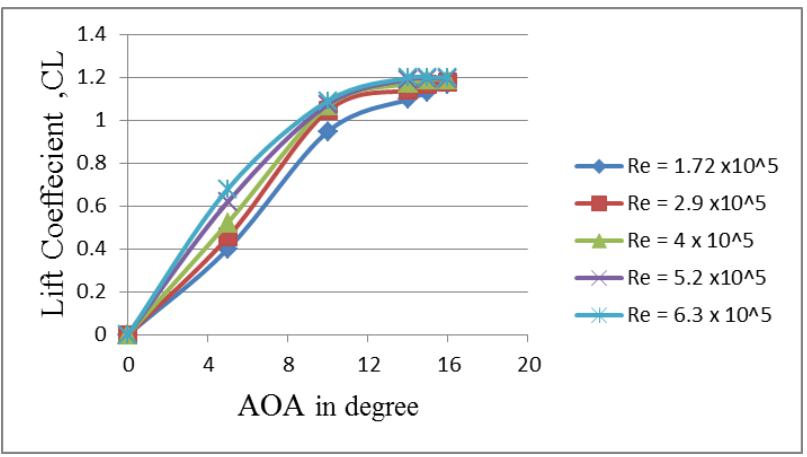

Figure (11): Variation of the lift coefficient with angle of attack of NACA 0015 with suction

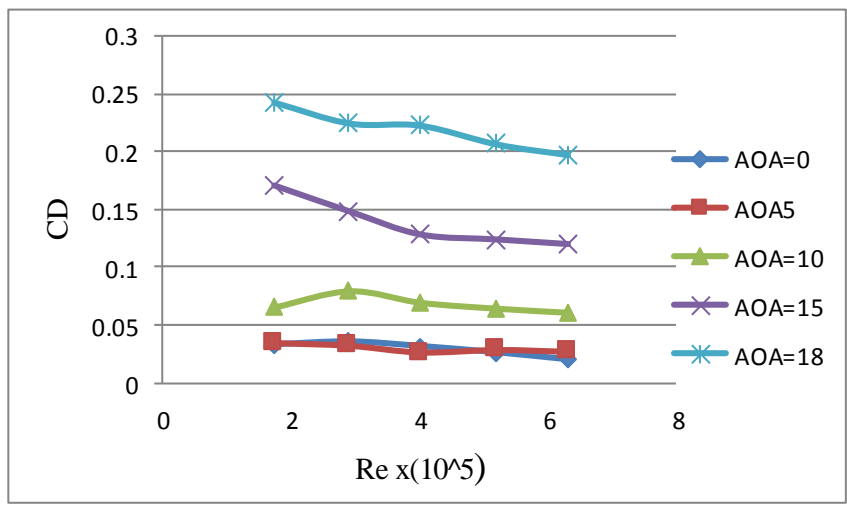

Figure (12) suction effect on the drag coefficient of NACA0015with suction

4.2 Aerodynamic Characteristics of NACA $0012 \& 4415$ The relationship between drag coefficient (CD) and Reynolds number is shown in figure (4.3). CD directly proportional with angle of attack (AOA) and increases in the Reynolds number values and maximum $C D$ values can be obtained at $15^{\circ} \mathrm{AOA}$ for all Re values, where stall was occurred. Also diagram explain that NACA 0012 exhibits high drag coefficient values than NACA 0015 and cambered NACA 4415. The variation of lift coefficient (CL) illustrated in the figure (4.5).

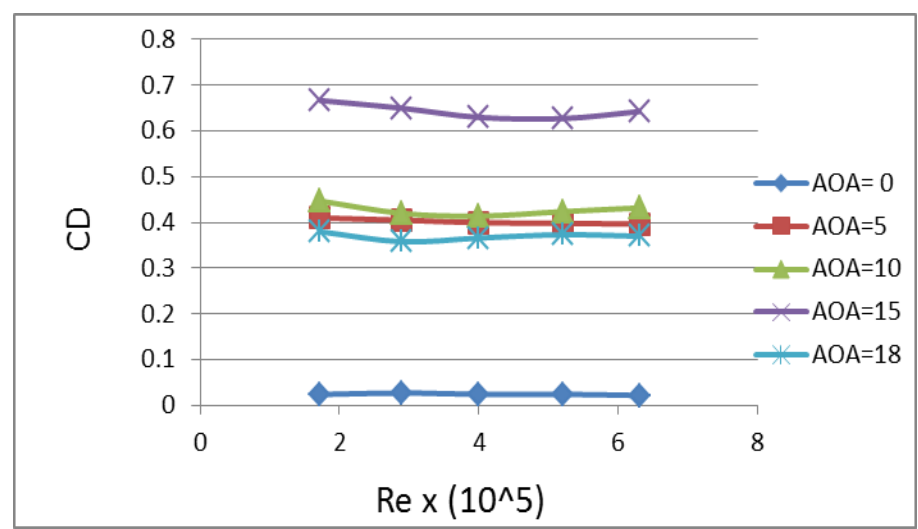

Figure (4.3): variation of the drag coefficient vs. Reynolds number for NACA 0012 at different AOA

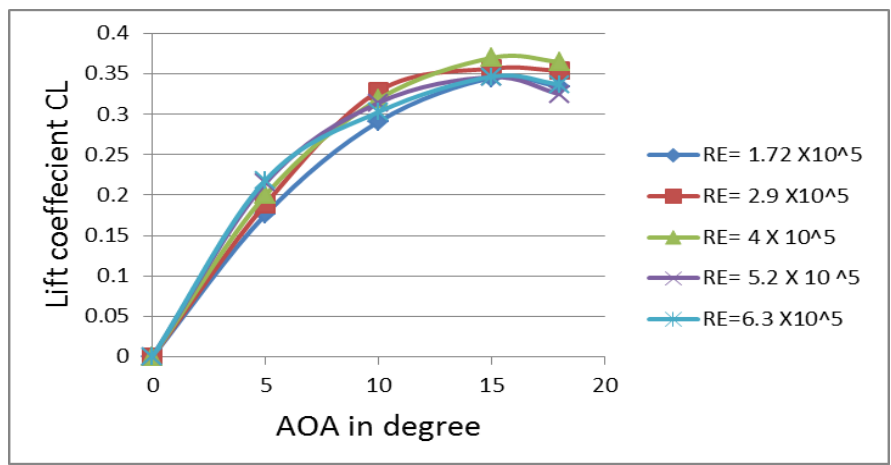

Figure (13): variation of the lift coefficient Vs. $\mathrm{AOA}^{0}$ NACA 4415 at different Reynolds number

\section{Conclusion}

The main goals in the current work is the study the effect of profile of three different air foils one of them has been improved using suction the delayed the boundary layer on the drag and lift forces at different Reynolds number and angles of attack. According to the results of the present study conclusions were deduced of the following: 1- Drag coefficient (CD) decreased when Reynolds number increased. Increasing the attack angle (AOA) induced dramatically increasing in the $\mathrm{CD}$ values.

2- Suction technique tends to increase the lift coefficient of NACA0015 approximately by $45 \%$ and this ratio decreased with increase AOA. Also the drag coefficient decreased due to suction the delayed boundary layer.

3. The cambered aerofoil (NACA 4415) appeared decreasing in the (CD) values in comparison with symmetrical aerofoil (NACA 0015 without suction and NACA0012).suction technique reduce the different between NACA4415 and NACA0015

4. NACA4415 exhibit large values lift coefficient than other NACA shapes which used in this study. So this profile le of the air foil is widely used in the aerodynamic application especially when high lift required, turbine blades etc.

5- NACA 0015 exhibit large values of lift coefficient at lower Re- number 


\section{Acknowledgments}

The authors want to thank dean of collage of engineering/University of thi- Qar technical staff of mechanical engineering department and special thank to Asst. Prof. Dr Adnan Al- Umary and chief of engineering Mr. Falih Al- Azawi for their help in conducting the experiments.

[1]B Saccharin, R Woszidlo, and I Wygnanski," On the significance of stream wise vortices in turbulent mixing and separation control applications", University of Berlin, thesis for the degree of Master science of Aerospace engineering, (2008).

[2] M. Gad-el-hack "Active and Reactive Flow Management", University of Cambridge Kingdom Press, thesis for the degree of Master science in Mechanical engineering, (2000).

[3] Anderson, J.D,'Fundamentals of aerodynamics" McGraw-Hill series in aeronautical and aerospace engineering $4^{\text {th }}$ edition. McGraw Hill, New York, 2007.

[4] Prof Mason's Applied and Computational Aero course http://www.aoe.vt.edu/aoe/faculty/Mason

f/CAtxtTop.html.

[5] Anderson, J.D, Jr," Fundamentals of Aerodynamics", Aeronautical and Aerospace Engineering $3^{\text {rd }}$ edition, McGraw-Hill Series, 2001.

[6] Cleaver, D.J., Wang, Z. and Gurus, I., "Investigation of High-Lift Mechanisms for a Flat-Plate Airfoil Undergoing Small-Amplitude Plunging Oscillations", J, AIAA, 2013, 4, 51.

[7] A.W. Ailor, W.R. Eberle," Configuration effects on the lift of body in close ground proximity", J. Aircraft, 1976, 13, 584.

[8] Sutherland HJ, Berg DE, "Ashwill TD. A retrospective of VAWT technology", J. Sandia National Laboratories, 2012.

[9] Kitsios, V, Kotapati, R, Mittal, R., Ooi, A., Soria, J., and You, D,"Numerical simulation of lift enhancement on a NACA 0015 airfoil using ZNMF jets ", J. Aerospace science, 2006, 3. 457.

[10] Victor Troshin, Avraham Seifert, "Performance recovery of a thick Turbulent airfoil using a distributed closed-loop flow control system", J. Experiments in Fluids, 2013, 54.

[11] L. H., T. N. Jukes, K. S. Choi and J. J. Wang", Flow control over a NACA 0012 airfoil using dielectric-barrierdischarge plasma actuator with a Gurney flap", J. Experiment in Fluids, 2012, 52. 